\title{
Prevalence of Vitamin A Deficiency in School Going Children in Rural Area
}

\author{
Kishor Pandurang Kadu', Smita Kishor Kadu², Santosh Yadavrao Ingle ${ }^{3}$, \\ Vishakha Tulshiram Vatkar ${ }^{4}$, Sharayu Ashok Bhore ${ }^{5}$ \\ ${ }^{1}$ Consultant, Epione Hospital, Amravati \\ ${ }^{2}$ Professor and Head, Department of Ophthalmology, Dr. Panjabrao Deshmukh Memorial Medical College and \\ Hospital, Amravati \\ ${ }^{3}$ Consultant, Epione Hospital, Amravati \\ ${ }^{4}$ Junior Resident, Department of Ophthalmology, Dr. Panjabrao Deshmukh Memorial Medical College and \\ Hospital, Amravati \\ ${ }^{5}$ Junior Resident, Department of Ophthalmology, Dr. Panjabrao Deshmukh Memorial Medical College and \\ Hospital, Amravati \\ Corresponding Author: Smita Kishor Kadu
}

\begin{abstract}
Background: Adequate data on occurrence of ocular morbidities associated with vitamin A deficiency amongst school going children was not available. So, our study was aimed to evaluate the prevalence of vitamin A deficiency among the primary school children in relation to socio-economical status.
\end{abstract}

Methods: The study was designed among school children of 5-15 years of age after taking consent form from principals of different schools in the rural areas of Amravati district in Maharashtra. A predesigned proforma was used to collect the information.

Results: Total 600 school children were examined for Vitamin A deficiency, out of which $314(52.50 \%)$ were boys and 286 $(47.75 \%)$ were girls. Among the school children $106(13.7 \%)$ students were under the age group of 5-10 years and $494(86.3 \%)$ students were 1115 years. According to modified Kuppuswamy scale of Socio-economic status 96 (16\%) students belongs to class III, 458 (76.33\%) students from class IV and $46(7.66 \%)$ students from class V. Prevalence of Vitamin A deficiency was observed in $34(5.7 \%)$ students, among them $6(17.64 \%)$ had conjunctival xerosis and $28(82.35 \%)$ had bitot's spot. Among 34 Vitamin A deficiency children 22 $(64.70 \%)$ were girls and $12(35.29 \%)$ were boys. Conclusion: The presence of ocular morbidity in relation to vitamin A deficiency was observed in students with low socio-economic classes.
Prevention, early intervention and treatment of ocular diseases by regular screening of students and nutritional education in schools would definitely decrease the risk of ocular abnormalities.

Key words: Vitamin A deficiency, xerophthalmia

\section{INTRODUCTION}

Vitamin A is one of the essential nutrients needed in small amounts for normal visual and immune functions, the maintenance of epithelial cellular integrity, growth and development ${ }^{[1,2]}$

In Vitamin A deficiency patients initially report night blindness (nyctalopia) due to rod photoreceptor dysfunction. As the disease progresses, the ocular epithelium becomes keratinized with the appearance of Bitot's spots, wrinkling of the conjunctiva, loss of goblet cells and replacement of the normal epithelium (xerosis). Corneal changes start with punctate keratopathy, and then progress to surface keratinization (corneal xerosis). Ulceration occurs when this keratinized layer detaches. In severe vitamin A deficiency, especially with concurrent protein malnutrition, the cornea stroma liquefies (keratomalacia), leading to a descematocele or corneal perforation with prolapse of intraocular contents. [3,4] 
Uncommonly, Vitamin A deficiency causes focal retinal pigment epithelium defects (xerophthalmic fundus). These are yellow and white spots in the peripheral retina causing scotoma. ${ }^{[3]}$

Critically, data on vitamin A status in Indian children is limited, given the potentially devastating yet reversible consequences, we sought to assess clinical features of vitamin A deficiency in Indian children to document the presence of ocular manifestations. By assessing the prevalence, we will be able to find the major symptoms which are a contributing factor to vitamin A deficiency in relations to socio- economical status.

\section{MATERIALS AND METHODS}

A community-based cross-sectional study was conducted on 600 school children aged between 5-15 years from selected schools were included in the study irrespective of their sex and previous vitamin A immunization status were included in the study at a health center situated in rural areas of Amravati district of Maharashtra. Children with age less than 5 years or more than 15 years were excluded from the study. All children with active respiratory disease, gastrointestinal diseases like diarrhoea and active skin infections were excluded from this study. Informed consent from school principal and teachers was obtained. The study protocol was approved by the Ethical Committee of Institution.

The study was carried out to gather information as per a predesigned proforma that included the identification data, socioeconomical status, diet history and ocular examination. Ocular examination was conducted by one ophthalmologist by a bright illuminant torch in natural light followed by slit lamp examination, dry eye evaluation with Schirmer's test, tear film break up time and fundus examination with direct ophthalmoscopy. If vitamin A deficiency was diagnosed then brief history of night blindness, or there were signs of conjunctival xerosis, keratinization, bitot's spots, corneal xerosis, keratomalacia and corneal scarring on clinical examination was done. History of night blindness was confirmed by asking mother whether the child faced any difficulty while playing or in identifying objects in dim light, especially at sun set, was recorded.

The socio economic status of the child's family was determined by using the modified Kuppuswamy scale. Education, occupation and income of both the father and mother were taken to calculate the socio economic status of the child. We have assessed Vitamin A deficiency clinically by using WHO classification as given in Table 1.

The primary data was compiled in Microsoft Office Spreadsheet 2016. Continuous variables as well as descriptive statistics were evaluated in the same spreadsheet. Further statistical analysis was done by using SPSS windows version 20.0 software.

Table 1. World Health Organization (WHO) classification of xerophthalmia ${ }^{[5]}$

\begin{tabular}{|l|l|l}
\hline $\mathrm{XN}$ & Night blindness \\
\hline $\mathrm{XIA}$ & Conjunctival xerosi & \\
\end{tabular}

$\mathrm{X} 1 \mathrm{~A}$ Conjunctival xerosis

\begin{tabular}{|l|l|l}
$\mathrm{X} 1 \mathrm{~B}$ & Bitot's spot \\
\hline
\end{tabular}

X2 Corneal xerosis

X3A Corneal ulceration/ keratomalacia $<1 / 3$ corneal surface

$\mathrm{X} 3 \mathrm{~B}$ Corneal ulcer/ keratomalacia $\geq 1 / 3$ corneal surface

\begin{tabular}{l|l}
\hline XS & Corneal scarring \\
\hline
\end{tabular}

XF Xerophthalmic fundus

\section{RESULTS}

Total 600 students undergone ophthalmology screening in this study, out of which 314 (52\%) were boys and 286 $(48 \%)$ were girls which was almost equal gender distribution. In the age group division $106(14 \%)$ were from 5-10 years i.e. from 5th standard and below this number was quite a low than $494(86 \%)$ of 6th standard and above, and these students cooperated well with complete ophthalmic evaluation during study period. 574 (97\%) children were of Hindu community as compare to $26(4 \%)$ of Muslim community. $458(76 \%)$ children were belonging to Class IV of modified Kuppuswamy scale of socioeconomic status which can defer their nutritional status as well as lifestyle. In 
other demographic details 328 (54\%) has joint family type of living condition. (Table 2)

\begin{tabular}{|c|c|c|}
\hline Variables & $\begin{array}{l}\text { No. of students } \\
(\mathrm{N}=600)\end{array}$ & Percentage \% \\
\hline \multicolumn{3}{|l|}{ Gender } \\
\hline Boy & 314 & 52.50 \\
\hline Girl & 286 & 47.75 \\
\hline \multicolumn{3}{|l|}{ Age } \\
\hline 5-10 years & 106 & 13.7 \\
\hline $11-15$ years & 494 & 86.3 \\
\hline \multicolumn{3}{|l|}{ Religion } \\
\hline Hindu & 574 & 95.7 \\
\hline Muslims & 26 & 4.3 \\
\hline \multicolumn{3}{|l|}{ Family type } \\
\hline Joint & 328 & 54.7 \\
\hline Nuclear & 272 & 45.3 \\
\hline \multicolumn{3}{|c|}{ Socio-economical status } \\
\hline Class III & 96 & 16 \\
\hline Class IV & 458 & 76.3 \\
\hline Class V & 46 & 7.66 \\
\hline
\end{tabular}

Table 3 : Prevalence of Vitamin A deficiency

\begin{tabular}{|l|l|l|l|}
\hline \multirow{2}{*}{ Category } & Variables & $\mathbf{N}(\mathbf{3 4})$ & Percentage \% \\
\hline \multirow{2}{*}{ Age } & Boy & 12 & 35.30 \\
\cline { 2 - 4 } & Girl & 22 & 64.71 \\
\hline \multirow{2}{*}{ Religion } & $5-10$ yrs & 14 & 41.18 \\
\cline { 2 - 4 } & $11-15$ yrs & 20 & 58.82 \\
\hline \multirow{2}{*}{ Socio-economical status } & Hindu & 30 & 88.24 \\
\cline { 2 - 4 } & Muslim & 4 & 11.76 \\
\cline { 2 - 4 } & Class I-III & 10 & 29.41 \\
\cline { 2 - 4 } Family type & Class IV-V & 24 & 70.59 \\
\hline & Joint & 14 & 41.17 \\
\cline { 2 - 4 } & Nuclear & 20 & 58.83 \\
\hline
\end{tabular}

34 children out of all 600 children found out to have vitamin A deficiency signs as per WHO classification of Vitamin A Deficiency. Gender wise, 22 girls and 12 boys had Vitamin A deficiency which suggests girls are more prone for Vitamin A deficiency along with their other nutritional deficiencies in school and adolescent age group. Similarly 20 Vitamin A deficiency children were from the age group of 11-15 years which is considered to be pubertal age group as compare to 14 from 5-10 years of age. Study participants from younger age groups were less, so it's difficult to analyze on this. Lower socio-economical grade IV and $\mathrm{V}$ had high prevalence of Vitamin $\mathrm{A}$ deficiency i.e. $24(70 \%)$ as compared to upper grade probably because of lifestyle and nutritional diversity. (Table 2)

During evaluation of all these 34 Vitamin A deficiency children, we found that $28(82 \%)$ were having bitot's spot as a major clinical finding of Vitamin A deficiency and $6(18 \%)$ had conjuctival xerosis. We could not get other signs of Vitamin A deficiency in them. (Table 4)

Table 4 : Ocular findings in association with Vitamin A deficiency among children

\begin{tabular}{|l|l|l|}
\hline Ocular findings & No. of students $(\mathbf{N}=\mathbf{3 4})$ & Percentage \\
\hline Conjunctival xerosis & 6 & $17.64 \%$ \\
\hline Bitot's spots & 28 & $82.35 \%$ \\
\hline
\end{tabular}

\section{DISCUSSION}

There is a substantial documentation of the prevalence, of vitamin A deficiency in preschool-aged children; extent of Vitamin A deficiency in older or adolescent age group children has not given much attention. Present study was carried out in primary school children (5-15 years age) from rural areas in Amravati district of Maharashtra to see the prevalence of Vitamin A deficiency.

In our present study out of 600 children aged between 5-15 years, prevalence of Vitamin A deficiency was observed in $34(5.7 \%)$ children which was lower than the prevalence of Vitamin A deficiency $(9.1 \%)$ among school children in Aligarh reported by Sachdeva et al. [6] Studies from various countries of Southeastern and Asian had shown Vitamin A deficiency ranging from $0.2 \%$ to $15 \%$ in school aged children. ${ }^{[7]}$ However, higher prevalence of ocular morbidity associated with Vitamin A deficiency has been reported from some states like Haryana (58.8\% in 4-18 years) and Rajasthan $(71.7 \%$ in $4-16$ years). ${ }^{[8]}$

We had highest number of cases observed in age group 11 to 15 years (58.8\%). The prevalence of Vitamin A deficiency was higher among girls compared to boys and the difference observed was statistically significant probably because of high requirement of nutritional need in adolescent and pubertal age group is high amongst girls than boys and it has high impact in rural areas. Similar observations was made with Chauhan et al and Bhattacharya et al. ${ }^{[\mathbf{9 , 1 0 ]}}$ The association of Vitamin A deficiency and its consequences with socio-economic status was higher in class IV and V, than in social 
class III which was similar to the earlier reports of Chauhan et al and Pal et al. ${ }^{[11]}$

The results of the present study strongly suggest that screening of school children for ocular morbidities should be done at regular intervals and it should become one of the prime aspects of the educational health programme. For this, school teachers should be oriented and trained in identifying common eye problems among school children so that these children can be referred for immediate treatment. They should also communicate awareness regarding ocular hygiene among school children. In this manner the occurrence of preventable causes of blindness among school children will be minimized.

\section{CONCLUSION}

The present study concludes that presence of ocular morbidity in relation to vitamin A deficiency was observed in students with low socio-economic classes and underweight students. Prevention, early recognition, prompt treatment of ocular diseases by regular screening of students and nutritional education in schools would definitely decreases the risk of ocular abnormalities.

\section{REFERENCES}

1. WHO. Global prevalence of vitamin A deficiency in populations at risk 1995-2005. WHO global database on vitamin A deficiency. Geneva: World Health Organization; 2009.

2. Arimond M, Ruel MT. Progress in developing an infant and child feeding index: an example using the Ethiopia demographic and health survey 2000. International Food Policy Research Institute Washington, DC; 2002.

3. Smith J, Steinemann TL. Vitamin A deficiency and the eye. Int. Ophthalmol. Clin. 2000; 40: 83 -91.
4. Sherwin JC, Reacher MH, Dean WH, Ngondi J. Epidemiology of vitamin A deficiency and xerophthalmia in at-risk populations. Trans. R. Soc. Trop. Med. Hyg. 2012; 106: $205-14.5$

5. Sommer, Alfred \& World Health Organization. (1995). Vitamin A deficiency and its consequences; a field gide to detection and control / Alfred Sommer, 3rd ed. World Health Organization.

6. Sachdeva S, Alam S, Beig FK, Khan Z, Khalique N. Determinants of Vitamin A Deficiency amongst Children in Aligarh District, Uttar Pradesh. Indian Pediatrics. 2011; 48:861-6.

7. Vision screening in school children. Training module. Danish Assistance to the National Programme for Control of Blindness. New Delhi, India: 1.

8. Khurana AK, Sikka KL, Parmar IPS, Aggarwal SK. Ocular morbidity among school children in Rohtak city. Indian J Public Health. 1984;28:217-20.

9. Chauhan NT, Trivedi AV, Khan IM, Talsania NJ. Prevalence of clinical vitamin A deficiency among primary school children in urban slums of Ahmedabad: a cross sectional study. Journal of Clinical and Diagnostic research. 2011;5(8):162730.

10. Bhattacharya RN, Shrivastava $P$, Sadhukhan SK, Lahiri SK, Chakravorty M, Saha JB. A study on visual acuity and Vitamin A deficiency among primary school students in Naxalbari village, Darjeeling district of West Bengal. Indian Journal of Public Health. 2004;48(4):171- 80.

11. Pal R. Vitamin a deficiency in Indian rural preschool-aged children. Ann Trop Med Public Health. 2009;2:11-4

How to cite this article: Kadu KP, Kadu SK, Ingle SY et.al. Prevalence of vitamin A deficiency in school going children in rural area. International Journal of Research and Review. 2021; 8(2): 1-4. 